\title{
Mikroplastik Pada Sedimen di Zona Pemukiman, Zona Perlindungan Bahari dan Zona Pemanfaatan Darat Kepulauan Karimunjawa, Jepara
}

\author{
Revo Raprika Kurniawan*, Jusup Suprijanto, Ali Ridlo \\ Departemen Ilmu Kelautan, Fakultas Perikanan dan Ilmu Kelautan, Universitas Diponegoro \\ Jl. Prof. H. Soedarto S.H, Tembalang, Semarang, Jawa Tengah 50275 Indonesia \\ Email: revoraprika11@gmail.com
}

\begin{abstract}
Abstrak
Karimunjawa merupakan salah satu kawasan Taman Nasional yang terdapat di Indonesia yang terdiri dari pulau-pulau dan terbagi menjadi beberapa zona yang disesuaikan menurut fungsi dan peruntukkannya. Penelitian ini bertujuan untuk mengetahui jenis dan kelimpahan mikroplastik pada sedimen di zona pemukiman, zona pemanfaatan darat, dan zona perlindungan bahari Kepulauan Karimunjawa, Jepara. Sampel sedimen diambil dengan menggunakan pipa di 3 lokasi yaitu Pelabuhan Perintis, Legon Lele, dan Cemara Kecil. Sampel dikeringkan kemudian dipisahkan berdasakan ukuran butir menggunakan sieve shaker. Sedimen yang terjebak dalam sieve ukuran 0,3 dan $0,1 \mathrm{~mm}$ direndam dalam $\mathrm{H}_{2} \mathrm{O}_{2} 30 \%$ selama 24 jam selanjutnya mikroplastik dipisahkan dari sedimen dengan $100 \mathrm{ml} \mathrm{ZnCl} \mathrm{Zn}_{2}$ densitas $1,5 \mathrm{~g} / \mathrm{cm}^{3} \mathrm{kemudian}$ disaring dengan menggunakan kerta Whatman No. 40. Mikroplastik diamati bentuk, warna, dan jumlah menggunakan mikroskop cahaya dengan perbesaran 100x dan diidentifikasi secara visual. Jenis mikroplastik ditentukan dengan Uji FT-IR. Hasil menunjukkan kelimpahan mikroplastik tertinggi ditemukan pada lokasi Legon Lele dengan jumlah sebesar 340 partikel $/ \mathrm{kg}$, pada Pelabuhan Perintis sebanyak 245 partikel/kg, dan pada Cemara Kecil sebanyak 245 partikel/kg. Bentuk mikroplastik yang ditemukan yaitu fragment, film, dan fiber. Jenis mikroplastik diduga yaitu HDPE, PVC, Polypropylene (PP), Polystrene (PS), ABS, Latex, LDPE, Nitrile, dan Nylon.
\end{abstract}

Kata kunci : Mikroplastik, Sedimen, Karimunjawa

\section{Abstract \\ Microplastic in Sediments of the Settlement Zones, Maritime Protection Zones and Land Use Zones of the Karimunjawa Islands, Jepara}

Karimunjawa is one of the National Park areas in Indonesia which consists of islands and is divided into zones which are adjusted according to their function and purpose. This study aims to determine the type and abundance of microplastics in sediments in residential zones, land use zones, and marine protection zones of the Karimunjawa Islands, Jepara. Sediment samples were taken using pipes in 3 locations, namely Perintis Harbor, Legon Lele, and Cemara Kecil. The sample is dried and then separated based on grain size using a sieve shaker. Sediments trapped in 0.3 and $0.1 \mathrm{~mm}$ sieve sizes were soaked in $30 \%$ $\mathrm{H} 2 \mathrm{O} 2$ for 24 hours and then microplastic was separated from sediments with $100 \mathrm{ml}$ of $\mathrm{ZnCl}$ density 1.5 $\mathrm{g} / \mathrm{cm}^{3}$ then filtered using Whatman No. kerta 40. Microplastic observed shapes, colors, and quantities using a light microscope with a magnification of $100 x$ and identified visually. Microplastic type was determined by FT-IR Test. The results showed the highest microplastic abundance was found at the Legon Lele location with an abundance of 340 particles $/ \mathrm{kg}$, at the Port of Pioneer as much as 245 particles / kg, and at Cemara Kecil as much as 245 particles $/ \mathrm{kg}$. Microplastic forms found are fragments, films, and fibers. Microplastic types are suspected namely HDPE, PVC, Polypropylene (PP), Polystrene (PS), ABS, Latex, LDPE, Nitrile, and Nylon.

Keywords : Microplastic, Sediment, Karimunjawa 


\section{PENDAHULUAN}

Kepulauan Karimunjawa merupakan wilayah Kecamatan di Kabupaten Jepara, Jawa Tengah yang terletak sebelah utara kota Jepara dengan jarak kurang lebih 45 mil atau $90 \mathrm{~km}$ dari ibukota Kabupaten Jepara (Setyono et al., 2013). Kepulauan Karimunjawa terbagi menjadi beberapa zonasi yaitu Zona Inti, Zona Perlindungan, Zona Pemanfaatan, Zona Rehabilitasi, Zona Pemanfaatan Perikanan Nasional, dan Zona Pemukiman. Setiap zona memiliki fungsi dan peruntukannya masingmasing. Kepulauan Karimunjawa memiliki keindahan alam dan panorama sehingga Karimunjawa sering dijadikan sebagai tempat destinasi wisata baik untuk wisatawan lokal ataupun mancanegara. Kegiatan pariwisata dan aktivitas manusia muncul masalah baru yaitu pencemaran sampah baik didarat dan dilaut.

Menurut Jambeck et al. (2015), Pada tahun 2010 Indonesia masuk dalam peringkat kedua dunia setelah Cina sebagai penghasil sampah plastik di perairan yaitu mencapai 187,2 juta ton. Data KLHK menyebutkan bahwa di Indonesia tahun 2008 sampah plastik mencapai 280.500 ton/hari. Rata-rata individu menghasilkan $0,12 \mathrm{~kg}$ sampah plastik/hari atau lebih dari 100 milyar kantong plastik setiap tahunnya. Pemakaian kantong plastik di Indonesia mencapai 700 kantong/orang/tahun.

Menurut Thompson et al. (2009), Plastik adalah susunan senyawa polimer yang memiliki struktur kaku terbentuk melalui proses polimerisasi monomer hidrokarbon membentuk rantai yang panjang. Plastik memiliki banyak fungsi dan digunakan dalam kehidupan sehari hari (Susilawati et al., 2011), namun plastik sulit terurai dan membutuhkan waktu yang lama untuk terfragmentasi secara sempurna. Sampah plastik yang terfragmentasi menjadi partikel yang sangat kecil disebut mikroplastik (Browne et al., 2011).

Menurut Arthur et al., (2009), mikroplastik merupakan jenis partikel plastik yang berukuran lebih kecil dari $5 \mathrm{~mm}$. Menurut Fendall \& Sewell (2009), mikroplastik terbagi dalam 2 jenis yaitu mikroplastik primer dan mikroplastik sekunder. Mikroplastik primer memiliki ciri sudah berukuran mikro, seperti pada limbah kosmetik dan sabun pencuci muka, sedangkan mikroplastik sekunder yaitu mikroplastik yang berasal dari fragmentasi plastik yang lebih besar.

Pencemaran mikroplastik bervariasi secara geografis dan lokasi. Faktor utama kelimpahan dan distribusi mikroplastik ditentukan oleh lingkungan (Veerasingam et al., 2016) dan faktor antropogenik (Sarafraz et al., 2016). Faktor lingkungan termasuk arus gelombang (Kim et al., 2015), pasang surut, siklon, arah angin (Sadri dan Thompson, 2014), dan hidrodinamika (Besseling et al., 2017) memiliki peran yang lebih besar dalam distribusi mikroplastik di laut daripada faktor antropogenik akibat aktivitas manusia yang mengarah pada akumulasi puing-puing plastik di lingkungan. Konsentrasi mikroplastik akan tinggi apabila faktor-faktor lingkungan ini lebih kuat (Brach et al., 2018).

Mikroplastik dengan densitas yang lebih besar dari air laut akan tenggelam dan menumpuk pada sedimen (Alomar et al., 2016), sedangkan mikroplastik dengan densitas rendah akan mengapung di permukaan laut (Suaria dan Aliani, 2014). Sedimen laut memiliki potensi untuk menumpuk atau sebagai tempat berkumpulnya mikroplastik (Nuelle et al., 2014), dan dapat menyebabkan pencemaran dalam jangka panjang pada sedimen (Cozar et al., 2014). Akumulasi mikroplastik di sedimen dapat membahayakan kehidupan laut dan manusia. Bagi biota laut mikroplastik dapat berdampak apabila terakumulasi didalam tubuh seperti sistem pertumbuhan, menghambat produksi enzim, menurunkan fungsi kerja hormon dan mengurangi efektivitas sistem reproduksi (Wright et al., 2013).

Keberadaan mikroplastik dipengaruhi oleh beberapa faktor yaitu jumlah sampah plastik yang berasal dari aktivitas antropogenik atau aktivitas manusia (Sarafraz et al., 2016), seperti kegiatan pariwisata, aktivitas pemukiman, aktivitas pengkapan ikan seperti alat tangkap nelayan dan limbah kapal nelayan (Ayuningtyas, 2019), dan faktor lingkungan seperti arus, gelombang, dan angin (Brach et al., 2018).

Penelitian mengenai kontaminasi mikroplastik di suatu wilayah darat atau sedimen dapat diketahui dengan mengambil dan menganalisis sampel sedimen yang bersal dari lokasi tersebut. Sampel sedimen diambil dari tiga lokasi yaitu Pelabihan Perintis (Zona Pemukiman), Legon Lele (Zona Pemanfaatan Darat), dan Cemara Kecil (Zona Perlindungan Bahari). Ketiga lokasi tersebut dipilih karena memiliki karakteristik yang berbeda sehingga diharapkan dapat mewakili seluruh kondisi sedimen di Taman Nasional Kepulauan Karimunjawa. Pelabuhan Perintis terletak pada 
zona pemukiman di Pulau Karimunjawa yang padat akan aktivitas pemukiman. Lokasi ini selain menjadi pelabuhan, juga menjadi pusat berkumpulnya warga yang beraktifitas sebagai nelayan dan jual beli ikan. Pulau Legon Lele termasuk dalam kawasan zona pemanfaatan darat. Lokasi ini dilindungi dan digunakan sebagai penangkaran penyu. Cemara Kecil termasuk zona pemanfaatan bahari. Cemara Kecil sering kali didatangi oleh wisatawan karena memiliki panorama yang indah sehingga terdapat kegiatan wisata pada lokasi ini. Tujuan dari penelitian ini yaitu untuk mengetahui jenis dan bentuk mikroplastik serta kelimpahan mikroplastik yang berada pada sedimen di Kepulauan Karimunjawa, Jepara.

\section{MATERI DAN METODE}

Materi yang digunakan dalam penelitian ini adalah sedimen yang berasal dari Pelabuhan Perintis, Pulau Cemara Kecil, dan Pulau Legon Lele. Titik pengambilan sampel ditampilkan pada Gambar 1. Titik koordinat setiap lokasi tersaji pada Tabel 1.

Pengambilan sampel dilakukan pada bulan Juli 2019 di 3 lokasi yaitu di Pelabuhan Perintis, Legon Lele, dan Cemara Kecil. Setiap lokasi terdapat 3 stasiun yang diambil secara acak. serta diukur parameter fisika dan kimia meliputi suhu, salinitas, kecerahan dan densitas sebagai data pendukung. Pengambilan sampel sedimen dilakukan dengan menggunakan pipa besi dengan panjang $30 \mathrm{~cm}$ dan berdiameter 3 inci. Pipa dimasukan ke dasar sedimen secara tegak lurus dengan menggunakan bantuan palu, kemudian pipa diangkat. Sedimen yang terambil langsung dipindahkan ke dalam ziplock untuk menghindari kontaminasi masuknya objek lain. Sedimen yang diambil sebanyak kurang lebih $1 \mathrm{~kg}$.

\section{Pengolahan Sampel Sedimen}

Sampel sedimen basah dikeringkan dengan cara dijemur di bawah sinar matahari dengan menggunakan kotak bening yang ditutup selama 2 hari. Tujuannya yaitu untuk mengindari kontaminasi pada sample. Kemudian sedimen kering sebanyak $200 \mathrm{~g}$ diayak menggunakan sieve shacker untuk mendapat ukuran butir yang diinginkan. Sieve shaker dihidupkan dan diatur pada kecepatan putaran $200 \mathrm{rpm}$ selama 10 menit (Cordova et al., 2016). Sampel yang terjebak pada setiap ukuran mesh (ukuran butirnya $2 ; 0,5 ; 0,3$; 0,125 ; dan $0,0625 \mathrm{~mm}$ ) ditimbang beratnya. Sampel yang terjebak diukuran mesh $0,3 \mathrm{~mm}$ dan $0,125 \mathrm{~mm}$ diambil untuk perlakuan selanjutnya.

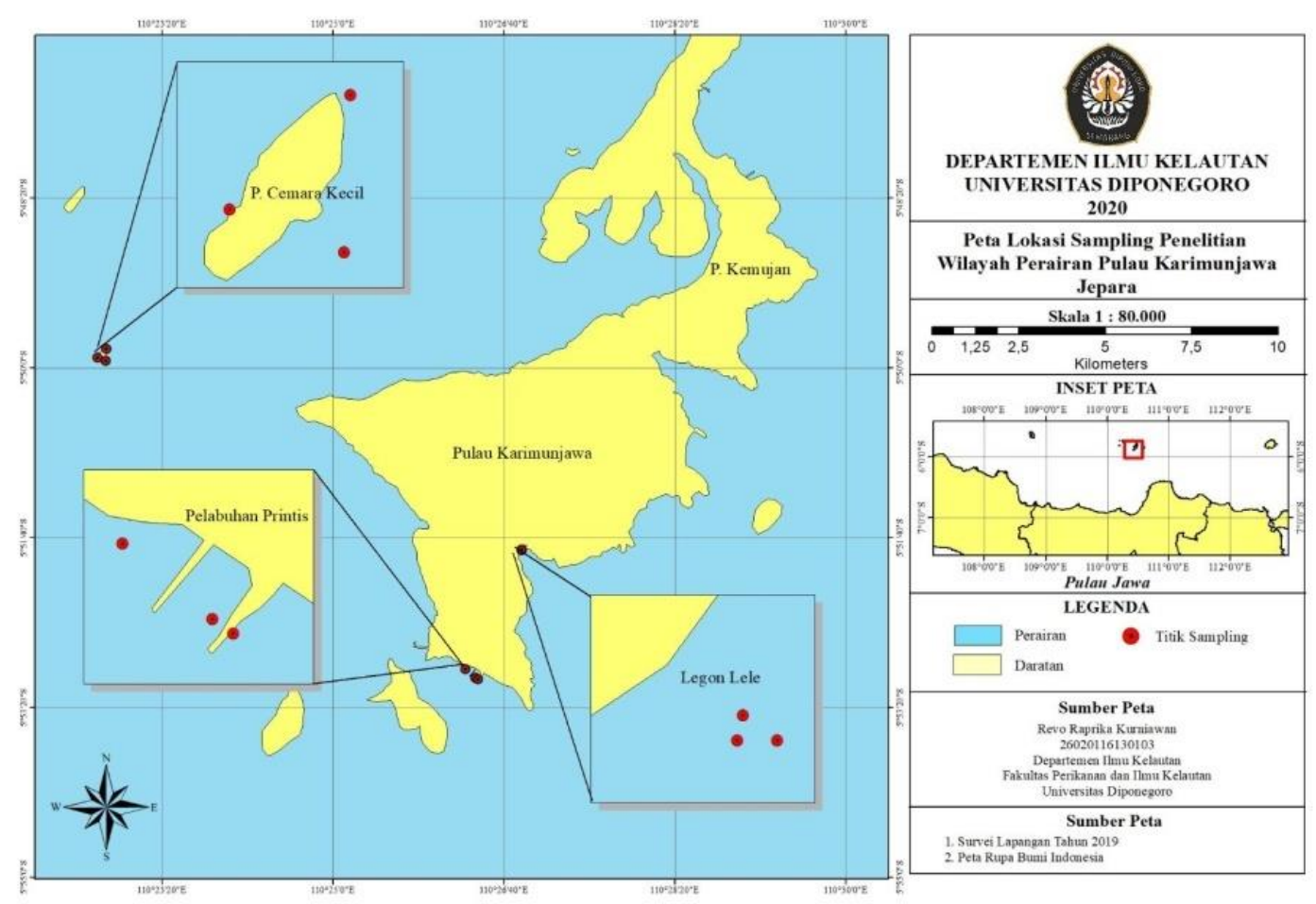

Gambar 1. Lokasi Penelitian 
Tabel 1. Koordinat Pengambilan Sampel

\begin{tabular}{|c|c|c|}
\hline Lokasi & Stasiun & Koordinat \\
\hline \multirow[t]{3}{*}{ Pelabuhan Printis } & 1 & S 05'52'57,11" E 110²6'17,92" \\
\hline & 2 & S 05'53'02,04" E $110^{\circ} 26^{\prime} 23,74^{\prime \prime}$ \\
\hline & 3 & S 05'53'02,99" E $110^{\circ} 26^{\prime} 25,11^{\prime \prime}$ \\
\hline \multirow[t]{3}{*}{ Cemara Kecil } & 1 & S 05'49'55,31" E 110²2'47,34" \\
\hline & 2 & S $05^{\circ} 49^{\prime} 53,45^{\prime \prime}$ E $110^{\circ} 22^{\prime} 42,40^{\prime \prime}$ \\
\hline & 3 & S 05'49'48,94" E 110²2'45,99" \\
\hline \multirow[t]{3}{*}{ Legon Lele } & 1 & S 0551'46,93" E $110^{\circ} 26^{\prime} 50,92^{\prime \prime}$ \\
\hline & 2 & S 05'51'46,97" E $110^{\circ} 26^{\prime} 50,64^{\prime \prime}$ \\
\hline & 3 & S $05^{\circ} 51^{\prime} 46,75^{\prime \prime}$ E $110^{\circ} 26^{\prime} 50,68^{\prime \prime}$ \\
\hline
\end{tabular}

\section{Penghilangan Bahan Organik dalam Sampel Sedimen}

Sedimen direndam dalam larutan $\mathrm{H}_{2} \mathrm{O}_{2} 30 \%$ sebanyak $50 \mathrm{~mL}$, diaduk agar tercampur secara rata dengan larutan, kemudian didiamkan selama 24 jam (Cordova et al., 2018).

\section{Fraksinasi Mikroplastik dari Sedimen}

Sampel sedimen direndam menggunakan larutan $\mathrm{ZnCl}_{2}$ dengan densitas $1.5 \mathrm{~g} / \mathrm{mL}$ sebanyak $100 \mathrm{~mL}$ (Lusher et al. 2007). diaduk sampai tercampur rata kemudian didiamkan selama 24 jam. Supernatan dipisahkan dari endapan dengan cara di dekantasi, selanjutnya supernatan disaring menggunakan kertas saring Whatman nomor 40 (diameter kertas: $45 \mathrm{~mm}$, pore size $20 \mu \mathrm{m}$ ) dengan menggunakan bantuan vacuum pump (Cordova et al., 2018).

\section{Identifikasi Bentuk Mikroplastik dengan Mikroskop}

Mikroplastik diamati bentuk, warna, dan dihitung jumlahnya menggunakan mikroskop cahaya dengan perbesaran 100x.dan diidentifikasi secara visual (Manalu et al., 2017). Hasil pengamatan di-capture, dilakukan pengukuran, dan dihitung setiap bentuknya (Hidalgo-Ruz et al. 2012).

\section{Identifikasi Jenis Mikroplastik dengan FT-IR}

Mikroplastik yang diperoleh dianalisis dengan spektrometer IR. Identifikasi dilakukan dengan cara mengamati puncak-puncak yang terdapat dalam spectra IR dan mencocokkan dengan vibrasi ikatan antar atom dan dibandingkan dengan Jung et al. (2018) dan Zhao et al. (2018).

\section{Menghitung Kelimpahan Mikroplastik pada Sedimen}

Kelimpahan mikroplastik didapatkan dari hasil perhitungan dengan cara jumlah partikel mikroplastik yang diperoleh per berat sedimen kering (Mauludy et al., 2019).

\section{Analisis Data}

Data kelimpahan partikel mikroplastik yang diperoleh diolah dengan menggunakan aplikasi pengolahan data Ms. Excel yang ditampilkan dalam bentuk histogram secara deskriptif.

\section{HASIL DAN PEMBAHASAN}

\section{Identifikasi Mikroskopik Mikroplastik}

Hasil pengamatan secara mikroskopis terhadap mikroplastik, ditemukan tiga bentuk mikroplastik yang ditemukan di ketiga lokasi Pelabuhan Perintis, Pulau Cemara Kecil, Pulau Legon Lele yaitu fiber, film, dan fragmen. Hasil pengamatan secara mikroskopis terhadap mikroplastik yang ditemukan pada sampel sedimen tersaji pada Gambar 2.

Tiap bentuk mikroplastik memiliki ciri dan karakteristik masing-masing. Fiber memiliki bentuk memanjang seperti serat, menyerupai benang atau senar pancing, memiliki warna-warna yang mencolok seperti biru dan merah diduga mikroplastik bentuk fiber ini berasal dari jaring atau senar pancing nelayan.

Film berbentuk lembaran dan sering ditemukan berwarna hitam. Diduga mikroplastik bentuk film ini berasal dari kantong plastik atau plastik pembungkus makanan atau minuman. Sedangkan mikroplastik fragmen berbentuk 
pecahan atau potongan plastik. Mikroplastik fragmen diduga berasal dari fragmentasi plastik botol, tutup botol, atau toples.

Perbedaan yang mencolok pada saat identifikasi antara film dan fragmen yaitu film hanya terlihat secara 2 dimensi karena bentuknya lembaran sedangkan fragmen terlihat memiliki bentuk 3 dimensi karena bentuknya berasal dari potongan atau pecahan dari plastik yang memiliki tekstur keras. Menurut Kingfisher (2011), film yaitu polimer plastik sekunder yang terfragmentasi dari plastik kantong atau plastik kemasan yang memiliki densistas rendah, sedangkan mikroplastik fragment yaitu hasil potongan produk plastik dengan polimer sintesis yang kuat.

\section{Jumlah Partikel Mikroplastik}

Jumlah partikel mikroplastik yang ditemukan pada sedimen di setiap lokasi tersaji pada Gambar 2. Ketiga bentuk mikroplastik ditemukan di seluruh lokasi. Pada Pelabuhan Perintis stasiun 1 ditemukan mikroplastik dengan jumlah 11 terdiri dari 3 fragment, 2 film, dan 8 fiber. Pada Pelabuhan Perintis stasiun 2 ditemukan mikroplastik dengan jumlah 18 terdiri dari 1 fragment, 2 film, dan 16 fiber. Pada Pelabuhan Perintis stasiun 3 ditemukan mikroplastik berjumlah 17 terdiri dari 2 fragment, 4 film, dan 11 fiber. Lokasi selanjutnya yaitu Legon Lele stasiun 1 ditemukan mikroplastik dengan jumlah 47 terdiri dari 16 fragment, 23 film, dan 8 fiber. Pada Legon Lele stasiun 2 ditemukan mikroplastik berjumlah 11 terdiri dari 1 fragment dan 10 fiber. Pada Legon Lele stasiun 3 ditemukan mikroplastik berjumlah 10 terdiri dari 2 fragment, 2 film, dan 6 fiber. Lokasi selanjutnya yaitu Cemara Kecil stasiun 1 ditemukan mikroplastik berjumlah 15 terdiri diri 3 fragment, 4 film, dan 8 fiber.
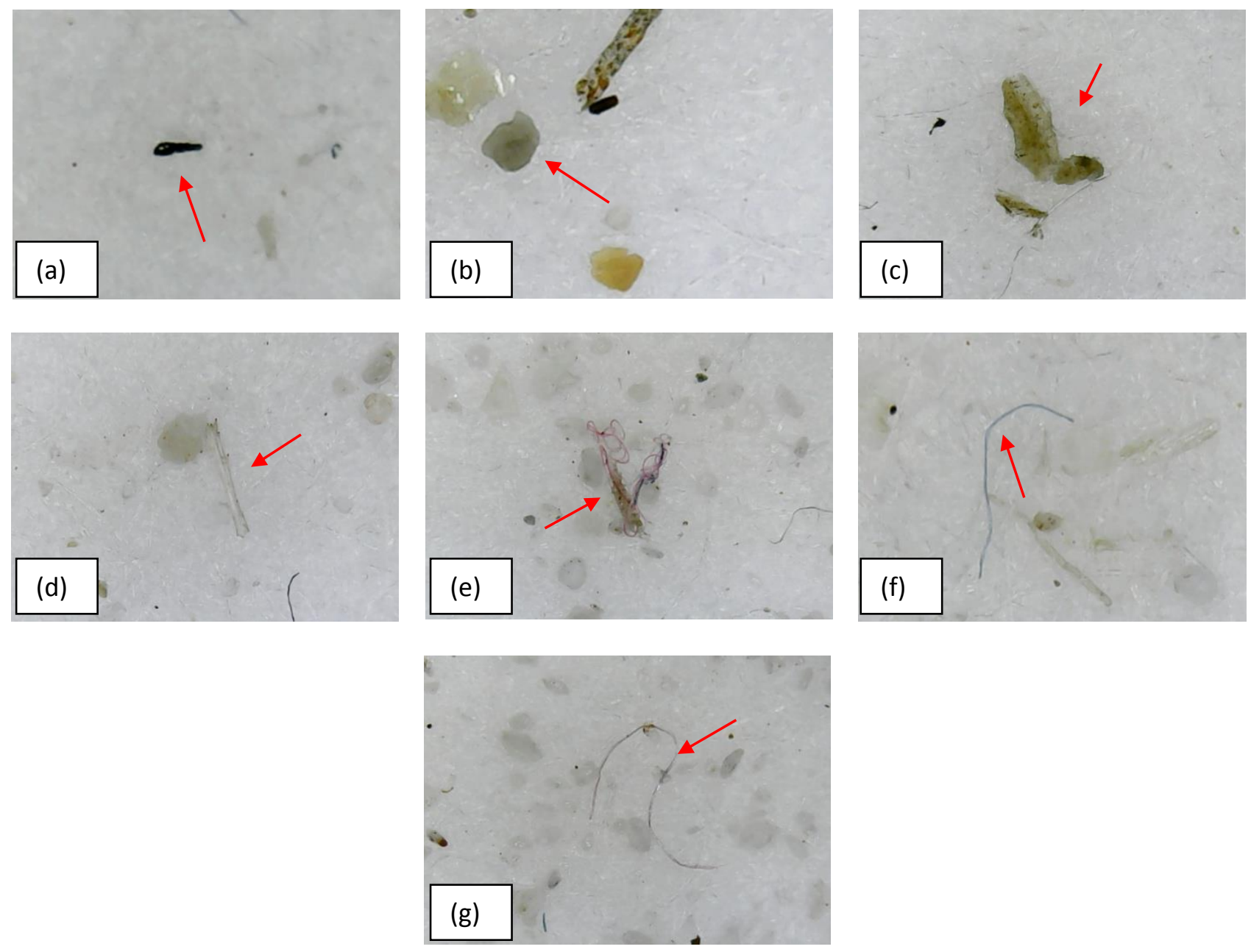

Gambar 2. Partikel Mikroplastik yang Ditemukan di Lokasi Pelabuhan Perintis, Pulau Cemara Kecil, dan Pulau Legon Lele (perbesaran 100x) (a,b) fragment, (c,d) film, (e,f,g) fiber 


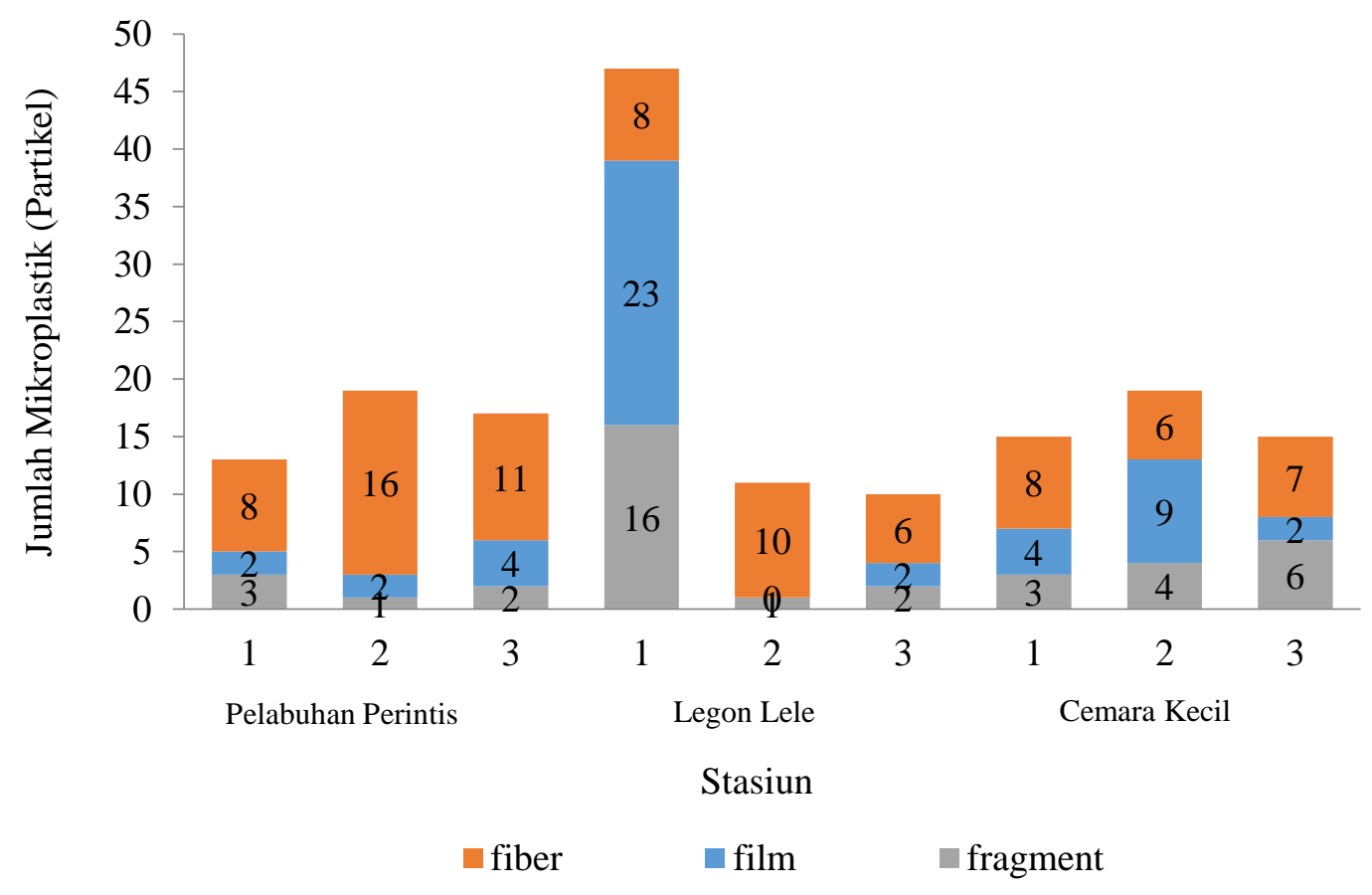

Gambar 2. Jumlah Partikel Mikroplastik di Sedimen

Pada Cemara Kecil stasiun 2 ditemukan mikroplastik berjumlah 19 terdiri diri 4 fragment, 9 film, dan 6 fiber. Pada Cemara Kecil stasiun 3 ditemukan mikroplastik berjumlah 14 terdiri dari 6 fragment, 2 film, dan 7 fiber. Jumlah partikel mikroplastik yang paling banyak ditemukan terdapat pada lokasi Legon Lele pada stasiun 1 dengan jumlah 47. Jumlah mikroplastik paling tinggi terdapat pada Legon Lele, hal ini dikarenakan pantai pada lokasi Legon Lele ditemukan banyak sampah yang yang terdapat pada pantainya, seperti jaring, kantong plastik, dan botol-botol bekas. Hal ini sesuai dengan Manalu et al. (2017), kelimpahan mikroplastik dipengaruhi oleh lokasi, keadaan, dan karakteristik di setiap pantainya.

\section{Kelimpahan Mikroplastik pada Sedimen}

Jumlah mikroplastik pada sedimen didapatkan dari hasil perhitungan dengan cara jumlah partikel mikroplastik yang diperoleh per berat sedimen kering (Mauludy et al., 2019). Kelimpahan mikroplastik pada sedimen berdasarkan bentuk dan berdasarkan lokasi penelitian tersaji pada Gambar 3 dan Gambar 4.

Berdasarkan hasil yang didapat jumlah mikroplastik pada sedimen terbagi menjadi dua yaitu berdasarkan lokasi dan berdasarkan bentuk.
Berdasarkan lokasi, pada Pelabuhan Perintis memiliki jumlah mikroplastik sebanyak total 245 partikel/kg. Pada Legon Lele memiliki jumlah mikroplastik sebanyak total 340 partikel $/ \mathrm{kg}$. Pada Cemara Kecil memiliki jumlah mikroplastik sebanyak total 245 partikel $/ \mathrm{kg}$.

Berdasarkan bentuknya jumlah mikroplastik, fiber sebanyak 400 partikel $/ \mathrm{kg}$, film sebanyak 240 partikel $/ \mathrm{kg}$, dan fragmen sebanyak 190 partikel $/ \mathrm{kg}$. Jumlah mikrolastik berdasarkan bentuk paling banyak yaitu fiber. Hal ini karena sebagian besar masyarakat di Karimunjawa bermata pencaharian sebagai nelayan. Banyak ditemukan sisa-sisa alat seperti jaring dan senar pancing di lokasi penelitian maupun yang terapung di permukaan laut dan berserakan di pantai.

Secara keseluruhan mikroplastik paling banyak ditemukan yaitu berada pada lokasi Legon Lele. Lokasi Legon Lele merupakan lokasi yang tidak terdapat aktivitas pemukiman pada lokasi tersebut dan hanya orang tertentu yang boleh masuk pada lokasi tersebut. Hal ini dikarenakan lokasi Legon Lele merupakan zona pemanfaatan darat. Sama seperti lokasi Cemara Kecil yang merupakan zona perlindungan bahari juga ditemukan banyak sampah. Pada lokasi - lokasi tersebut ditemukan banyak sampah seperti plastik, 
jaring nelayan, dan botol yang berserakan. Kemungkinan sampah - sampah tersebut terbawa oleh arus. Hal ini sesuai dengan Ayuningtyas (2019), persebaran mikroplastik dipengaruhi oleh kondisi arus dan masukan dari darat. Sedangkan pada lokasi Pelabuhan Perintis ditemukan mikroplastik karena pada lokasi tersebut merupakan tempat berkumpulnya masyarakat Karimunjawa seperti aktifitas pelabuhan, aktifitas nelayan, dan jual beli ikan. Kemungkinan mikroplastik dihasilkan dari kegiatan tersebut. Hal ini sesuai dengan Dewi et al. (2015), bahwa limbah plastik dapat dihasilkan dari aktivitas pelabuhan misalnya plastik yang berasal dari kantong plastik pembungkus ikan, alat tangkap nelayan, dan cat kapal.

\section{Identifikasi Jenis Mikroplastik dengan FT-IR}

Identifikasi dilakukan dengan cara mengamati puncak-puncak yang terdapat dalam spektra IR dan mencocokkan dengan vibrasi ikatan antar atom dan dibandingkan dengan Jung et al. (2018) dan Zhao et al. (2018).

Secara umum kesembilan spektra IR mikroplastik yang diperoleh dapat dibedakan menjadi 2 kelompok. Pelabuhan Perintis stasiun 3, Legon Lele stasiun 1 dan 3, dan Cemara Kecil stasiun 2 dan 3 menunjukkan kemiripan, sedangkan spektra IR Pelabuhan Perintis stasiun 1 dan 2, mirip dengan Legon Lele stasiun 2, dan Cemara Kecil stasiun 1. Spektrum IR mikroplastik pada masing - masing lokasi ditampilkan pada Gambar 5, 6, dan 7.

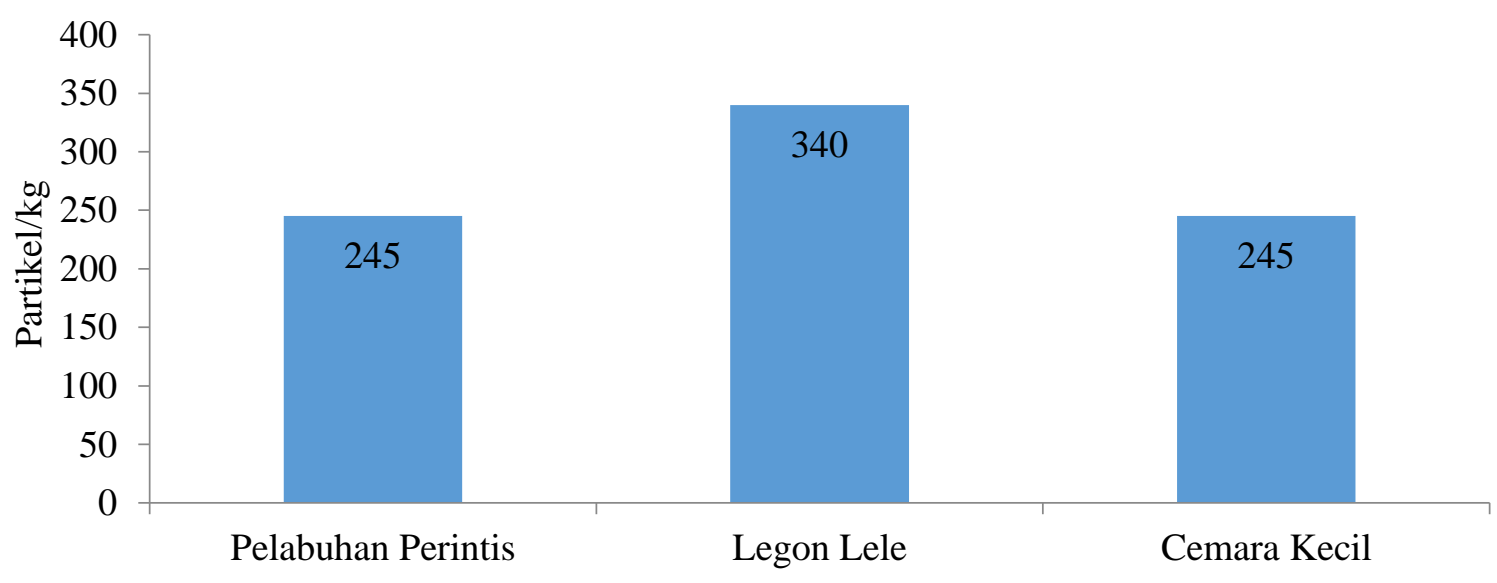

Lokasi

Gambar 3. Kelimpahan Mikroplastik pada Sedimen Berdasarkan Lokasi

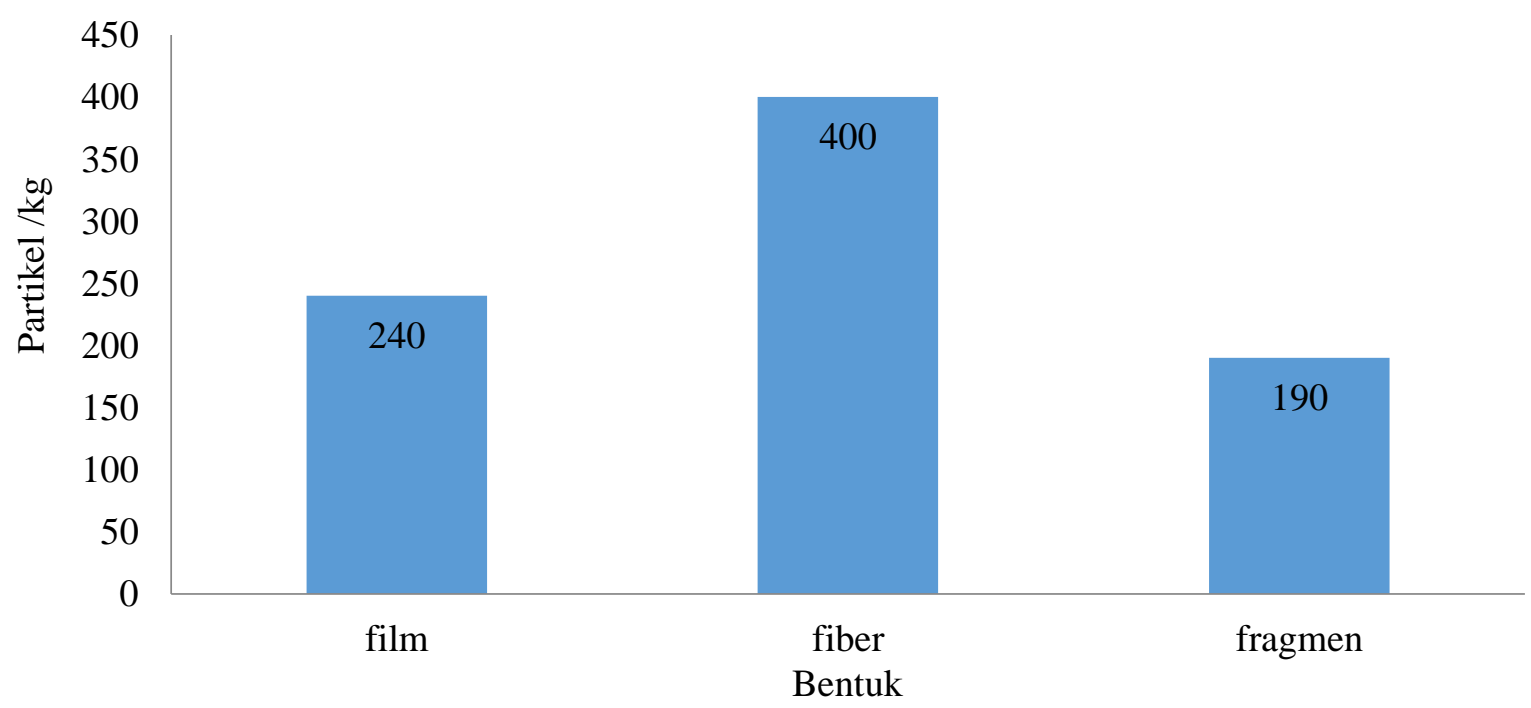

Gambar 4. Kelimpahan Mikroplastik pada Sedimen Berdasarkan Bentuk 


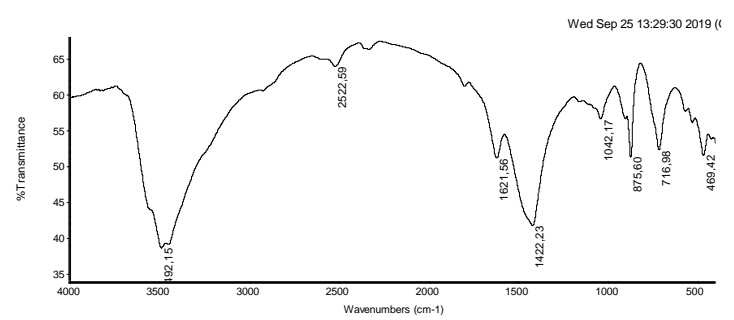

Stasiun 1

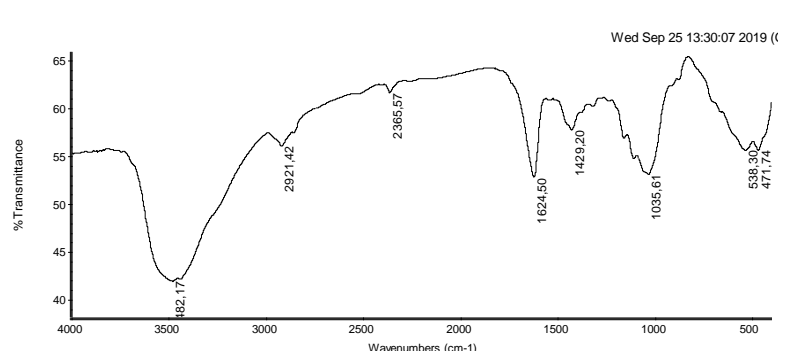

Stasiun 2

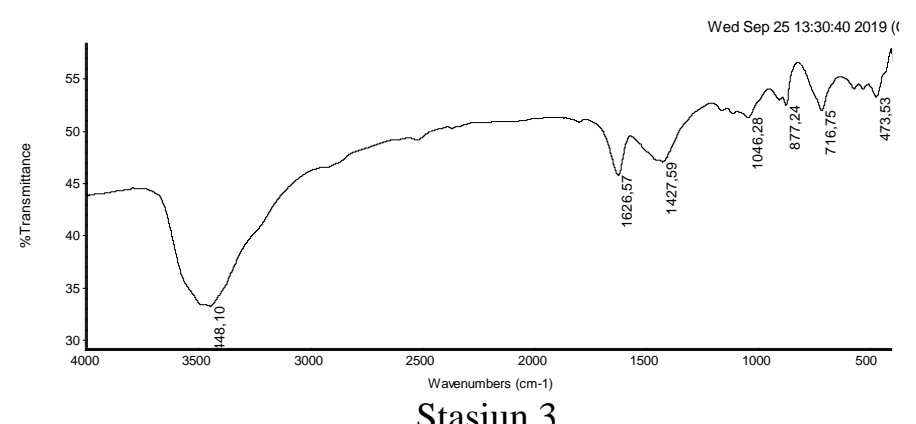

Gambar 5. Spektrum IR Mikroplastik Lokasi Pelabuhan Perintis

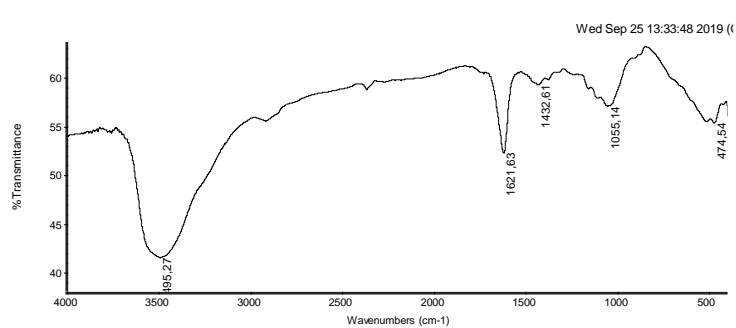

Stasiun 1

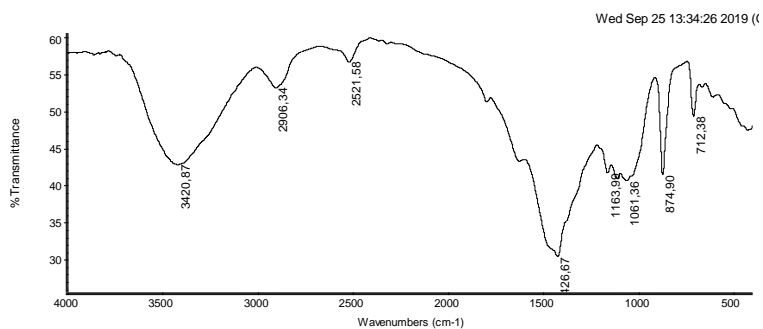

Stasiun 2

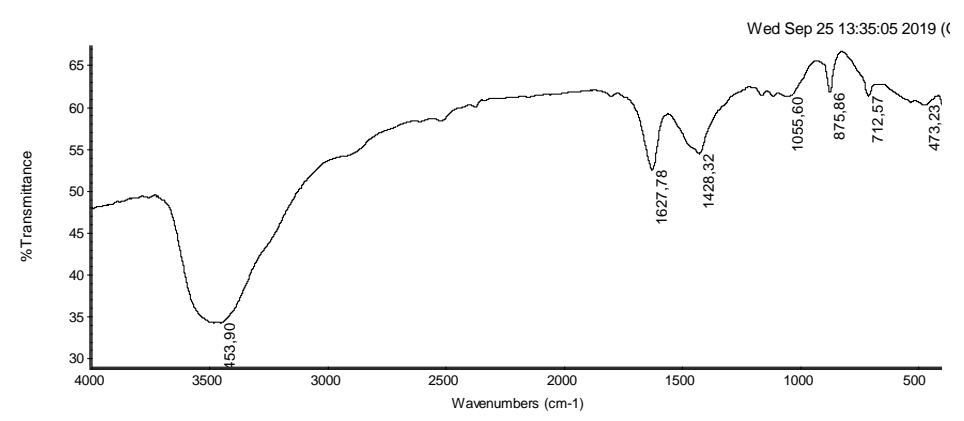

Stasiun 3

Gambar 6. Spektrum IR Mikroplastik Lokasi Legon Lele

Bentuk fiber adalah mikroplastik jenis PP, Nitrile, dan Nylon (Zhao et al., 2018). Hal ini di dukung oleh spektra IR yang menunjukkan adanya puncak pada bilangan gelombang 2900 $\mathrm{cm}^{-1}$ yang menunjukkan ikatan $\mathrm{C}-\mathrm{H}$, bilangan gelombang $1620 \mathrm{~cm}^{-1}$ menunjukkan ikatan $\mathrm{C}=\mathrm{C}$, $1430 \mathrm{~cm}^{-1}$ menunjukkan ikatan $\mathrm{CH}_{2}$, dan 1160 $\mathrm{cm}^{-1}$ menunjukkan ikatan C-O. Menurut Jung et al. (2018), Nylon merupakan salah satu sumber mikroplastik fiber. Fiber dapat berasal dari 

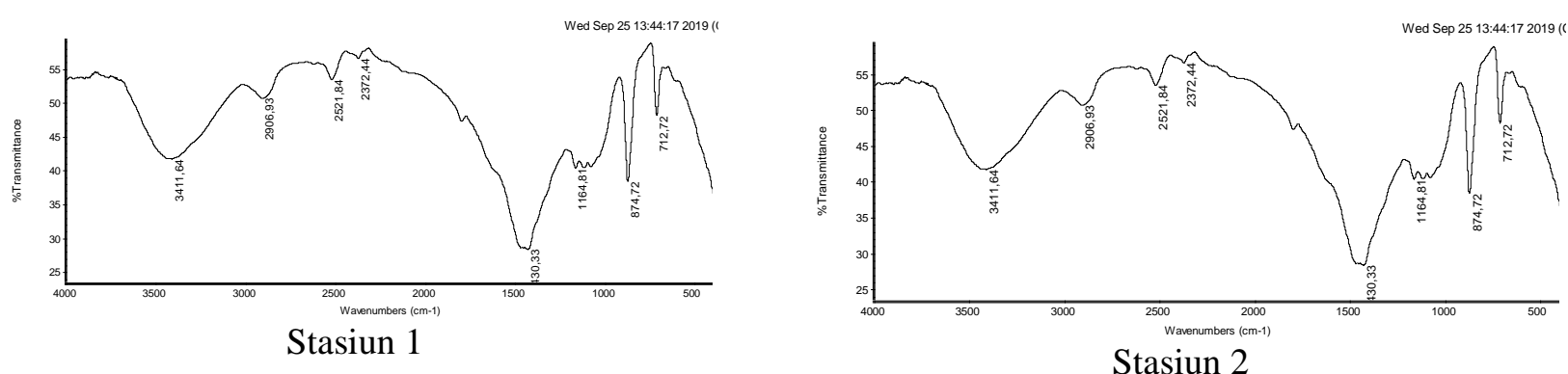

Stasiun 2

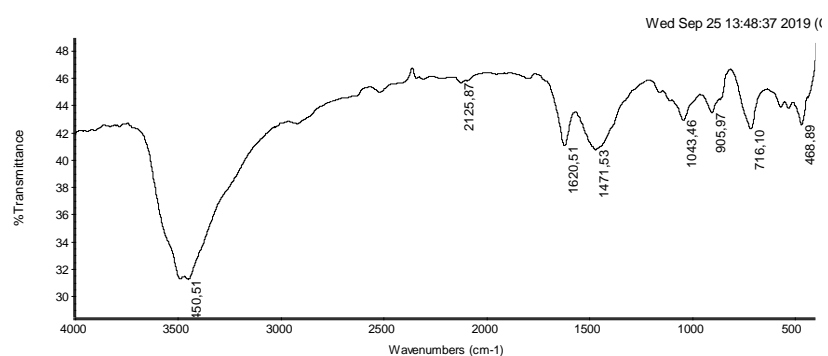

Stasiun 3

Gambar 7. Spektrum IR Mikroplastik Lokasi Cemara Kecil

penggunaan alat tangkap ikan seperti senar pancing dan jaring yang sebagian besar berasal dari jenis Nylon serta serat-serat pakaian yang dicuci ataupun yang terdegradasi. Menurut Zhao et al. (2018), Polypropylene (PP) merupakan sumber mikroplastik fiber. Penggunaan PP semakin banyak digunakan dalam industri tekstil untuk memproduksi pakaian, kain bukan tenunan dan karpet (Park et al., 2004).

Bentuk fragmen adalah mikroplastik jenis HDPE. PVC, dan ABS (Zhao et al., 2018) dan Jung et al. (2018). Hal ini di dukung oleh spektra IR yang menunjukkan adanya puncak pada bilangan gelombang 2900, $\mathrm{cm}^{-1}$ yang menunjukkan ikatan C-H, $1620 \quad \mathrm{~cm}^{-1}$ menunjukkan ikatan $\mathrm{C}=\mathrm{C}$, gelombang $1430 \mathrm{~cm}^{-1}$ menunjukkan ikatan $\mathrm{CH}_{2}$, dan $716 \mathrm{~cm}^{-1}$ menunjukkan ikatan $\mathrm{CH}_{2}$. Menurut Jung et al. (2018), HDPE, PVC, dan ABS merupakan sumber mikroplastik fragmen. Hal itu karena jenis plastik tersebut memiliki tekstur yang keras dan massa jenis yang besar. HDPE dan PVC sering ditemukan sebagai tutup botol, wadah shampoo, dan pipa peralon.

Bentuk film adalah mikroplastik jenis Latex, LDPE, dan PS. Hal ini di dukung oleh spektra IR yang menunjukkan adanya puncak pada bilangan gelombang 2900/cm yang menunjukkan ikatan $\mathrm{C}-\mathrm{H}, \quad 1430 \quad \mathrm{~cm}^{-1}$ menunjukkan ikatan $\mathrm{CH}_{2}$, gelombang $1160 \mathrm{~cm}^{-1}$. menunjukkan $\mathrm{C}=\mathrm{C}, 1030 \mathrm{~cm}^{-1}$ menunjukkan ikatan $\mathrm{C}-\mathrm{H}$, dan $716 \mathrm{~cm}^{-1}$ menunjukkan ikatan $\mathrm{CH}_{2}$. (Jung et al., 2018), Pencemaran mikroplastik film dapat bersumber dari potongan kantong kresek, plastik pembungkus makanan, dan berbagai macam plastik tipis lainnya. Menurut Jung et al. (2018), mikroplastik film biasanya mengapung pada kolom air karena memiliki massa jenis yang rendah, seperti jenis Latex, Polystrene, dan LDPE. Kantong kresek berasal dari jenis LDPE dan plastik pembungkus makanan berasal dari jenis PS. Menurut Cordova et al. (2018), polystyrene banyak digunakan sebagai wadah makanan atau minuman.

\section{KESIMPULAN}

Hasil penelitian ditemukan bahwa Kepulauan Karimunjawa khususnya Pelabuhan Perintis, Legon Lele, dan Cemara Kecil sudah terpapar polutan mikroplastik pada sedimennya. Berdasarkan bentuknya, mikroplastik yang paling banyak ditemukan yaitu bentuk fiber dengan jumlah 400 partikel $/ \mathrm{kg}$, film sebanyak 240 partikel $/ \mathrm{kg}$, dan fragmen sebanyak 190 partikel $/ \mathrm{kg}$. Mikroplastik paling banyak ditemukan di lokasi Legon Lele yaitu dengan jumlah 340 partikel/kg, 
Pelabuhan Perintis sebanyak 245 partikel $/ \mathrm{kg}$, dan Cemara Kecil sebanyak 245 partikel/kg. Hasil spektra IR, mikroplastik yang ditemukan diduga berasal dari jenis HDPE, PVC, PP, PS, ABS, Latex, LDPE, Nitrile, dan Nylon.

\section{DAFTAR PUSTAKA}

Alomar, C., Estarellas, F. \& Deudero, S.. 2016. Microplastics in the Mediterranean Sea: Deposition in coastal shallow sediments, spatial variation and preferential grain size. Marine Environmental Research, 115:1-10. doi: 10.1016/j.marenvres.2016.01.005

Arthur, C., Baker, J., \& Bamford, H. 2009. Proceedings of the International Research Workshop on the Occurrence, Effects, and Fate of Microplastic Marine Debris.

Ayuningtyas, W.C., Yona, D., Julinda S.H. \& Iranawati, F. 2019. Kelimpahan Mikroplastik Pada Perairan Di Banyuurip, Gresik, Jawa Timur. Journal of Fisheries and Marine Research., 3(1):41-45. doi: 10.21776/ub.jfmr. 2019.003.01.5

Besseling, E., Quik, J.T.K. \& Sun, M. 2016. Fate of nano- and microplastic in freshwater systems: A modeling Study. Environmental Pollution., 220:540-548. doi: 10.1016/j.env pol.2016.10.001

Brach, L., Deixonne, P., Bernard, M.F., Durand. E. 2018. Anticyclonic eddies increase accumulation of microplastic in the North Atlantic subtropical gyre. Marine Pollution Bulletin., 126:191-196. doi: 10.1016/j.mar polbul.2017.10.077

Browne, M.A., Crump, P., Niven, S.J., Teuten, E., Tonkin, A., Galloway, T., \& Thompson, R. 2011. Accumulation of microplastic on shorelines woldwide: Sources and sinks. Environmental Science \& Technology., 45(21):9175-9179. doi: 10.1021/es201811s

Cordova, M.R. \& Wahyudi, A.J. 2016. Microplastic in the Deep-Sea Sediment of Southwestern Sumatera Waters. Marine Research in Indonesia., 41(1):27-35. doi: 10.14203/mri.v41i1.99

Cordova, M.R., Hadi, T.A \& Prayudha, B. 2018. Occurrence and abundance of microplastics incoral reef sediment: a case study in Sekotong, Lombok-Indonesia. AES Bioflux. 10(1):23-19. doi: 10.5281/zenodo. 1297719

Dewi, I.S., Budiarsa, A.A \& Ritonga, I.R. 2015. Distribusi mikroplastik pada sedimen di
Muara Badak, Kabupaten Kutai Kartanegara. Jurnal Depik., 4(3):121-131. doi: 10.13170/ depik.4.3.2888

Fendall, L.S., \& Sewell, M.A. 2009. Contributing to marine pollution by washing your face: Microplastics in facial cleansers. Marine Pollution Bulletin, 58(8):1225-1228. doi: 10.1016/j.marpolbul.2009.04.025

Hidalgo-Ruz, V., Gutow, L., Thompson, R.C. \& Thiel, M. 2012. Microplastics in the Marine Environment: A Review of the Methods Used for Identification and Quantification

Hiwari, H., Purba, N.P., Ihsan, Y.N., Yuliadi, L.P.S. \& Mulyani, P.G.. 2019. Kondisi Sampah Mikroplastik di Permukaan Air Laut Sekitar Kupang dan Rote, Provinsi Nusa Tenggara Timur. Prosiding Seminar Nasional Masyarakat Biodiversitas Indonesia 5(2):165171. doi: $10.13057 / \mathrm{psn} \mathrm{mbi} / \mathrm{m} 050204$

Jambeck, J.R., Geyer, R., Wileox, C. \& Siegler, T.R. 2015. Plastic waste inputs from land into the ocean. Marine Pollution., 347(6223):768-771. doi: 10.1126/science. 12 60879

Jung M.R. 2018. Validation of ATR FT-IR to Identify Polymers of Plastic Marine Debris, Including Those Ingested by Marine Organisms. Marine Pollution Bulletin., 127:704-716. doi: 10.13057/psnmbi/m050204

Kingfisher, J. 2011. Micro-plastic debris accumulation on puget sound beaches. Port Townsend Marine Science Center.

Lusher, A.L., Welden, N.A., Sobral, P. \& Cole, M. 2017. Sampling, Isolating, and Identifying Microplastics Ingested by Fish and Invertebrates. Anal Methods, 9:13461360. doi: 10.1039/ c6ay02415g

Manalu, A.A., Hariyadi, S. \& Wardiatno, Y. 2017. Microplastics abundance in coastal sediments of Jakarta Bay, Indonesia. ACCL Bioflux., 10(5):1164-1173.

Masura, J., Baker, J., Foster, G. \& Arthur, C. 2015. Laboratory methods for the analysis of microplastics in the marine environment: recommendations for quantifying synthetic particles in waters and sediments. NOAA Technical Memorandum NOSOR\&R-48, 39 pp.

Nuelle, M.T., Dekiff, J.H., Remy, D. \& Fries, E. 2014. A new analytical approach for monitoring microplastics in marine sediments. Environmental Pollution., 184:161-169. doi: 10.1016/j.envpol.2013.07.027 
Park, C.H., Kang, Y.K. \& Im, S.S.. 2004. Biodegradability of cellulose fabrics. Journal of Applied Polymer Science., 94(1):248-253. doi: 10.1002/app.20879

Purwaningrum, P. 2016. Upaya Mengurangi Timbulan Sampah Plastik di Lingkungan. Jurnal Teknik Lingkungan., 8(2):141-147. doi: 10.25105/urbanenvirotech.v8i2.1421

Rahmadani, S. 2019. Pemanfaatan Pati Batang Ubi Kayu dan Pati Ubi Kayu untuk Bahan Baku Alternatif Pembuatan Plastik Biodegradable. Jurnal Teknologi Kimia Unimal., 8(1):26-35. doi: 10.29103/jtku.v8i1. 1913

Sadri, S.S. \& Thompson, R.C. 2014. On the quantity and composition of floating plastic debris entering and leaving the Tamar Estuary, Southwest England. Marine Pollution Bulletin., 8(1):55-60. doi: 10.1016/ j.marpolbul.2014.02.020

Sarafraz, J., Rajabizadeh, M. \& Kamrani, E. 2016. The preliminary assessment of abundance and composition of marine beach debris in the northern Persian Gulf, Bandar Abbas City, Iran. Journal of the Marine Biological Association of the United Kingdom., 96(1):131-135. doi: 10.1017/S0025315415 002076

Suaria, G. \& Aliani, S. 2014. Floating debris in the Mediterranean Sea. Marine Pollution Bulletin., 86:494-504. doi: 10.1016/j.marpol bul.2014.06.025

Susilawati, Mustafa, I. \& Maulina, D. 2011. Biodegradable Plastics from a Mixture of Low Density Polyethylene (LDPE) and Cassava Starch with the Addiction of Acrylic Acid. Jurnal Natural. 11(2):69-73.
Septian F.M., Purba, N.P., Agung, M.U.K., Yuliadi, L.P.S., Akuan, L.F. \& Mulyani, P.G. 2018. Sebaran Spasial Mikroplastik di Sedimen Pantai Pangandaran, Jawa Barat. Jurnal Geomaritim Indonesia., 1(1):1-8.

Setyono, H., Musa, M. \& Handoyo, G. 2013. Peramalan Pasang di Perairan Pulau Karimunjawa, Kabupaten Jepara, Menggunakan Program "Worldtides". Jurnal Oseanografi., 3(1):1-7.

Storck, F.R., Kools, S.A.E. \& Rinck-Pfeiffer, S. 2015. Microplastic in fresh water resources, in: Science Brief. Global Water Research Coalition, Australia, p.7.

Thompson, R.C., Swan, S.H. \& Moore, C.J. 2009. Our Plastic Age. Philosophical Transactions of the Royal Society B. 364:1973-1976. doi: 10.1098/rstb.2009.0054

Veerasingam, S., Saha, M. \& Suneel, V. 2016. Characteristics, seasonal distribution and surface degradation features of microplastic pellets along the Goa coast, India. Chemosphere., 159:496-505. doi: 10.1016/ j.chemosphere.2016.06.056

Wright, S.L., Rowe, D., Thompson, R.C. \& Galloway, T.S. 2013. Microplastic ingestion decreases energy reserves in marine worms. Current Biology, 23(23):1031-1033. doi: 10.1016/j.cub. 2013.10.068

Zhao, J., Ran, W., Teng, J., Liu, Y. \& Liu, H. 2018. Microplastic pollution in sediments from the Bohai Sea and the Yellow Sea, China. Science of the Total Environment., 640-641:637-645. doi: 10.1016/j.scitotenv.20 18.05.346 